\title{
IOGURTE DE JUÇARA: FORMULAÇÃO E CORRELAÇÃO ENTRE OS PARÂMETROS REOLÓGICOS
}

\author{
D.H.G. PELEGRINE ${ }^{1}$, G. ARAÚJO² \\ ${ }^{1}$ Escola de Engenharia de Lorena (EEL/USP), Departamento de Engenharia Química \\ ${ }^{2}$ Universidade de Taubaté, Departamento de Ciências Agrárias \\ E-mail para contato: dhguima@usp.br
}

\begin{abstract}
RESUMO - Da mesma família do Açaí, o Juçara é bastante encontrada no Brasil, próxima aos rios e matas úmidas. Além do sabor apreciado, a fruta é refrescante, energética e de valor nutricional. Por ser um produto perecível há interesse na fabricação de derivados, tais como o iogurte, com elevado valor nutricional e grande aceitabilidade. $\mathrm{O}$ trabalho proposto incluiu $\mathrm{O}$ desenvolvimento de formulações do iogurte partir da polpa do Juçara e a análise da viscosidade do produto. Os resultados mostraram que o iogurte apresentou certa tixotropia, visto que o produto dessorou na medição da segunda repetição, ficando com características diferentes da inicial. $O$ teor da cultura lática não influenciou significativamente no comportamento reológico do iogurte; já o teor de polpa influenciou nos parâmetros reológicos do produto, sem do este mais consistente na formulação onde foi utilizado um teor de polpa de $10 \%$.
\end{abstract}

\section{INTRODUÇÃO}

Açaí é uma palmeira típica da Região Amazônica, cuja produção concentra-se nos estados do Pará e Amazonas sendo comercializado para outras regiões apenas na forma de polpa. (Reis e Guerra,1999). Da mesma família do Açaí, a Palmeira Juçara (E. Edulis Mart.) também conhecida como Juçara (ou Palmito-doce) é bastante encontrada na Mata Atlântica e também no cerrado, perto dos cursos dos rios e matas úmidas, da Bahia ao Rio Grande do Sul, facilitando o contado direto com o fruto. O Juçara, além de ter um sabor bastante apreciado, trata-se de uma fruta refrescante, energética e por ser rica em lipídios apresenta também vitamina A, ferro e água (Mortara e Valeriano, 2001).

Por outro lado, um dos grandes problemas do comércio, não apenas do Juçara, mas de qualquer fruta in natura, é a alta perecibilidade, mesmo sob refrigeração. Segundo Alexandre et al (2004), o Juçara é altamente perecível, sendo seu tempo máximo de conservação de 12 horas, mesmo sob refrigeração. O fator responsável por esta alta perecibilidade é a elevada carga microbiana que juntamente com a degradação enzimática são responsáveis pelas alterações de cor e pelo aparecimento do sabor azedo. Há cerca de dez anos, a conservação vem sendo feita pelo processo de congelamento, o que eleva significativamente o custo do produto.

É neste contexto que surgem diversas tentativas em se reduzir os desperdícios, resultantes desta grande perecibilidade do produto; dentre estas, destaca-se a produção dos derivados da fruta, tais como suco, néctar, sorvete, sobremesa gelificada, iogurte, etc, produtos esses que são muito apreciados no Brasil e no exterior, tendo portanto boas 
perspectivas de mercado. Dentre estes produtos, o iogurte ocupa posição de destaque, devido ao elevado valor nutricional e à grande aceitabilidade, tanto por crianças quanto por adultos, além de amenizar o problema de perecibilidade do leite, pois o seu estado liquido e sua composição nutritiva o torna propenso a danificação por microorganismos, tanto aqueles originalmente nele presentes quanto os introduzidos na manipulação do produto (Tadini and Collet, 2002; Santana et al., 2006). O iogurte constitui excelente fonte de múltiplas vitaminas, minerais e proteínas, ajudando também na produção de anticorpos, hormônios e enzimas, importantes para o metabolismo, contribuindo para reforçar o sistema imunológico e, consequentemente, retardar o envelhecimento (Nobre et al, 2006).

Por outro lado, é fundamental o conhecimento das propriedades físicas e químicas da polpa submetida ao processamento do iogurte, assim como do produto final, o qual deverá ser transportado em tubulações até a embaladeira, nos processos industriais. Dentre estas propriedades, o comportamento reológico ocupa posição de destaque, sendo útil não só como medida de qualidade, mas também em projetos, avaliação e operação dos equipamentos processadores de alimentos (tais como bombas, sistemas de agitação, tubulações,...) evitandose, desta maneira, um sub ou super dimensionamento (Pelegrine and Mascigrande, 2011).

Aqui, vale ressaltar que no Brasil, devido à escassez de dados sobre propriedades reológicas das frutas nacionais, a maioria dos equipamentos processadores dos derivados de frutas são projetados de acordo com os dados reológicos das frutas produzidas no exterior. Porém, a matéria-prima brasileira apresenta características diferentes daquelas produzidas em outras partes do mundo, principalmente no que diz respeito aos teores de sólidos. Para uma indústria processadora de iogurte, somente a economia de energia gerada pela determinação das propriedades reológicas da polpa da fruta, devido à maior precisão nos projetos de bombas, tubulações e pasteurizadores, já é motivo suficiente para incentivar o levantamento de dados de viscosidade, os quais devem ser determinados com a máxima precisão possível (Silva et al., 2005; Cunha et al., 2008).

\section{MATERIAL E MÉTODOS:}

Para a obtenção da polpa de Juçara, a matéria prima adquirida em palmeiras localizadas no Departamento de Ciências Agrárias da Unitau foi muito bem lavada com solução de água clorada, descascada e desprovidas das sementes. A colheita das hastes foi feita pelo método tradicional, sendo os frutos retirados das hastes e selecionados, retirando-se os verdes ou estragados. Em seguida, os mesmos foram peneirados para remoção da sujeira. As frutas foram selecionadas dentro de um recipiente e lavadas com água corrente, passando depois pelo processo de branqueamento, onde as mesmas passaram por descanso em água quente até a casca e a polpa começar a se soltar.

Logo após o branqueamento a polpa passou pela despolpadeira (Marca Makanuda) separando totalmente a polpa, da casca e da semente onde, posteriormente, foi adicionada de água para obtenção de uma polpa mais líquida e menos viscosa. Por fim, a polpa foi envasada e congelada sob temperatura inferior à $20^{\circ} \mathrm{C}$. Após realizado todo este processo a polpa foi avaliada físico-quimicamente. 


\subsection{CARACTERIZAÇÃO DA POLPA}

Para a caracterização das polpas foram, inicialmente, realizadas análises físico-químicas para a determinação da sua composição centesimal. Para a caracterização do material foram, inicialmente, realizadas análises físico-químicas para determinação da sua composição centesimal. Para tal caracterização, foram realizadas as seguintes análises físico-químicas: $\mathrm{pH}$ (Adolfo Lutz, 4.7.1); Umidade (A.O.A.C., 1980 - Method 16192); Teor de Sólidos Totais e Solúveis (Adolfo Lutz, 315/IV); Teor de Lipídios Totais (Bligh \& Dyer, 1959); atividade de água (utilizando equipamento medidor de atividade de água).

\subsection{PREPARO DO IOGURTE}

O iogurte foi preparado de acordo com a seguinte formulação: leite em pó desnatado, água filtrada, cultura lática, polpa de juçara. Primeiramente foi pesado o leite em pó desnatado suficiente para 11 com $12 \%$ de sólidos não gordurosos para, em seguida, diluir em água filtrada. Em seguida, o leite em pó reconstituído foi transferido para um béquer, sendo este aquecido até $43^{\circ} \mathrm{C}$. Uma vez atingida a temperatura de $43^{\circ} \mathrm{C}$, a cultura lática foi acrescentada, na proporção de $10 \%$ para, em seguida, a mistura ser homogeneizada durante 2 minutos. Passados 30 minutos, a temperatura do banho foi ajustada para $40^{\circ} \mathrm{C}$. Ao se observar a formação do coagulo firme, sem a liberação de soro, o aquecimento foi então interrompido. A seguir a polpa de Juçara foi adicionada, numa proporção de 10\% (e posteriormente, 15\%) da massa do iogurte. Em seguida o processo foi repetido com 5\% e 10\% de cultura lática.

\subsection{DETERMINAÇÃO DAS PROPRIEDADES REOLÓGICAS DO IOGURTE DE JUSASARA}

O comportamento reológico das diferentes formulações do iogurte de Juçara foi analisado em um viscosímetro rotativo da marca Brookfield Engineering Laboratories (modelo LV), sendo os ensaios foram realizados em triplicata, sendo utilizada uma nova amostra para cada repetição.

\section{RESULTADOS E DISCUSSÕES:}

\subsection{Caracterização da polpa}

As análises fisico-químicas da polpa de juçara foram realizadas em triplicata, sendo os valores de $\mathrm{pH}$, teor de sólidos solúveis, insolúveis apresentados a seguir: 
Tabela 1: Propriedades físico-químicas da polpa de juçara:

\begin{tabular}{c|c}
\hline Análises & Resultados \\
\hline $\mathrm{pH}$ & $6,0(0,000)$ \\
Teor de umidade $(\%)$ & $86,19(2,140)$ \\
Atividade de água & $0,952(0,012)$ \\
Teor de sólidos solúveis e totais $(\%)$ & $27,5(1,025)$ \\
Teor de lipídeos $(\%)$ & $2,174(0,086)$ \\
Teor do sólidos insolúveis $(\%)$ & $5,99(0,092)$ \\
\end{tabular}

Dos resultados apresentados na Tabela 1 pode-se verificar que, com relação à composição centesimal da polpa de juçara, esta apresentou composição característica do produto, de acordo com Nascimento et al. (2008).

\subsection{Comportamento reológico do iogurte de juçara}

A influência da quantidade de cultura láctica acrescida ao produto está ilustrada nas Figuras 1 e 2.

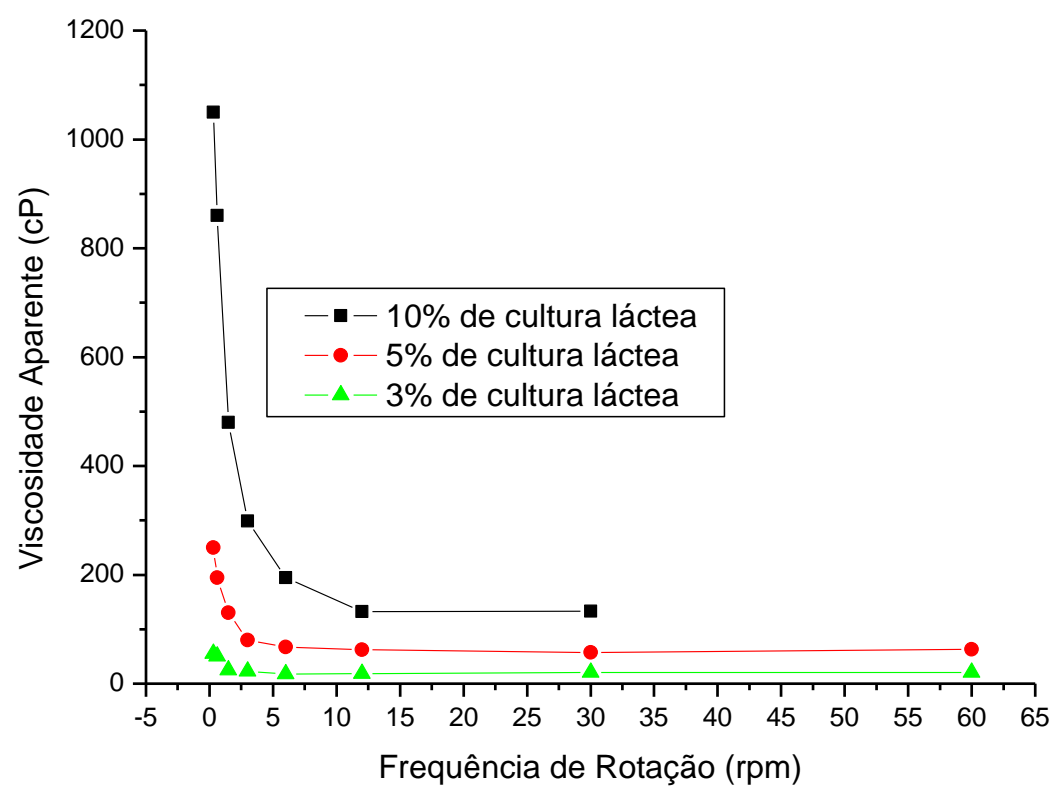

Figura 1: Reologia iogurte elaborado com $10 \%$ de polpa. 


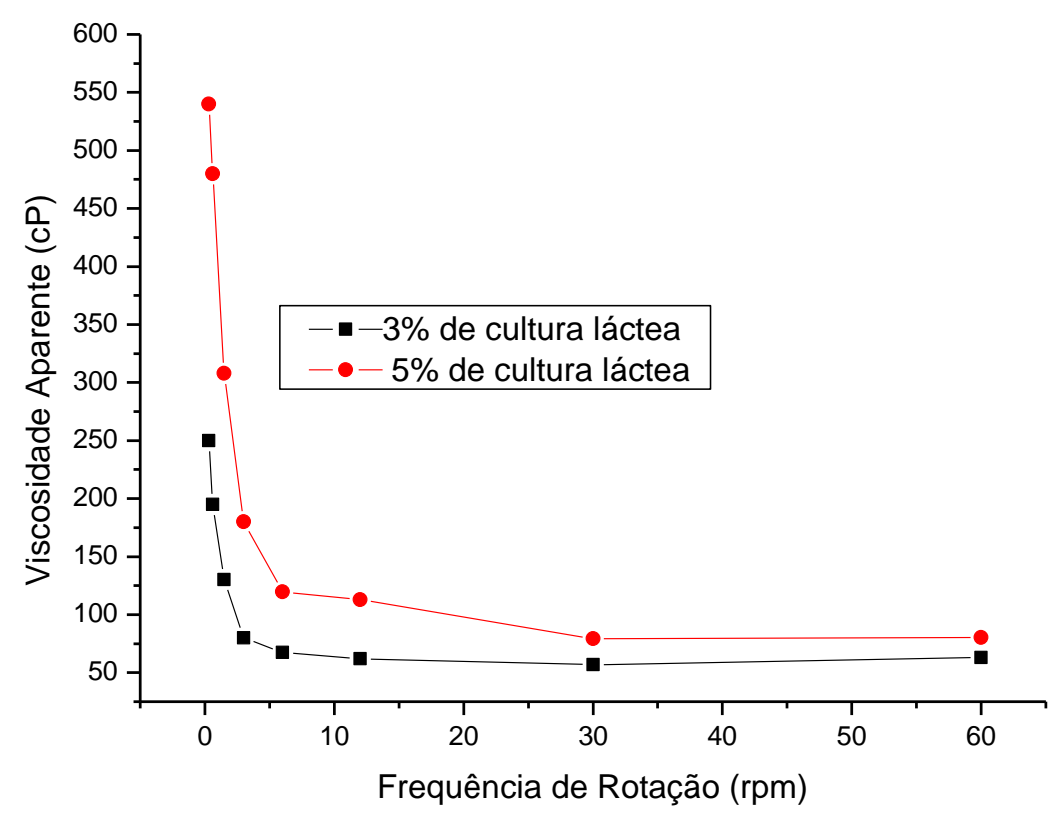

Figura 2: Reologia iogurte elaborado com $15 \%$ de polpa.

Com relação às diferentes formulações do iogurte, de acordo com a Figura 1, pode-se observar que, quando $10 \%$ de polpa de juçara foi acrescido à formulação, o produto com $10 \%$ de cultura lática foi o que apresentou consistência mais próxima à de um iogurte batido, enquanto as demais formulações apresentaram-se bem menos consistentes, semelhantes à consistência de uma bebida láctea não fermentada. Quando $15 \%$ de polpa de juçara foi acrescido à formulação, o produto com $10 \%$ de cultura láctica tornou-se altamente viscoso, o que impossibilitou a determinação da sua viscosidade aparente, resultando em leituras fora de escala no viscosímetro. Para este caso, o iogurte com 5\% de cultura láctica foi o que apresentou consistência mais próxima à de um iogurte batido.

Iodelis (2009) e Aguiar (2010), ao analisarem a influência do teor de cultura láctica no comportamento reológico do iogurte de goiaba observaram que o teor de cultura láctica pouco influenciou na viscosidade da polpa de goiaba. A justificativa para tal discrepância reside na composição físico química particular de cada fruta, assim como nos diferentes tamanhos e configurações das suas partículas suspensas, podendo interagir com maior ou menor intensidade com os componentes presentes no leite fermentado.

A influência do teor de polpa de furta a ser acrescido à formulação está ilustrada nas Figuras 3 e 4. 


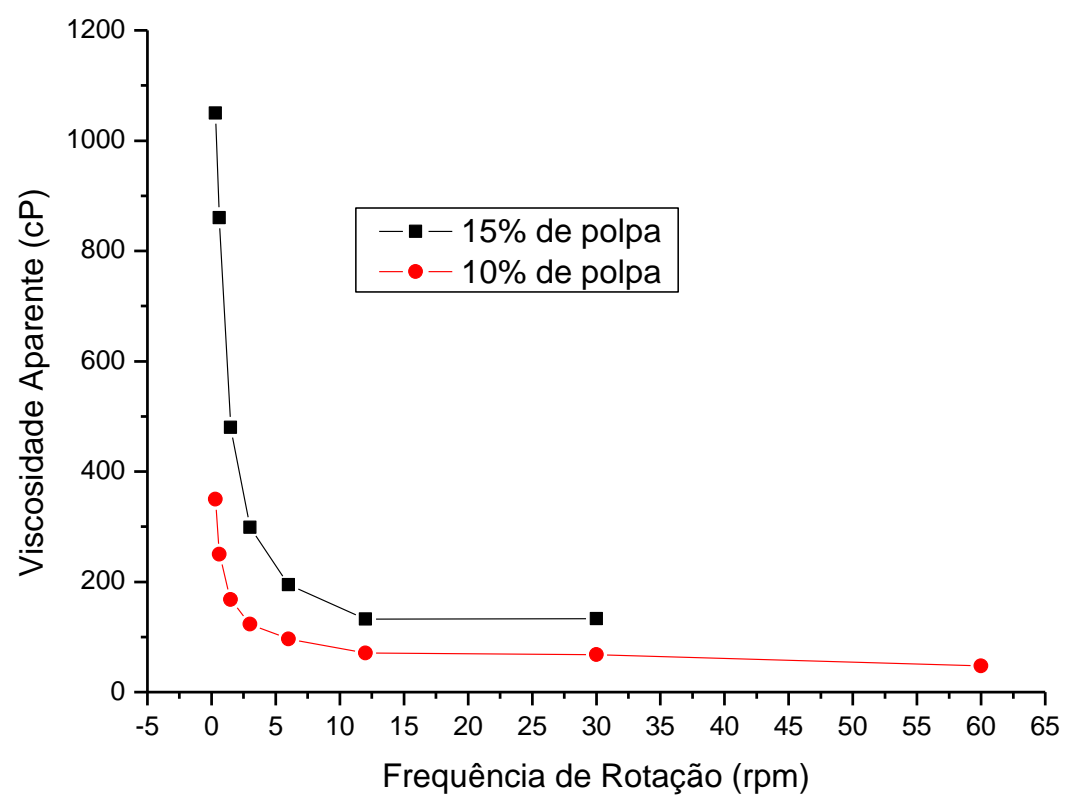

Figura 3: Influência da quantidade de polpa na viscosidade do iogurte elaborado com $3 \%$ de cultura láctica.

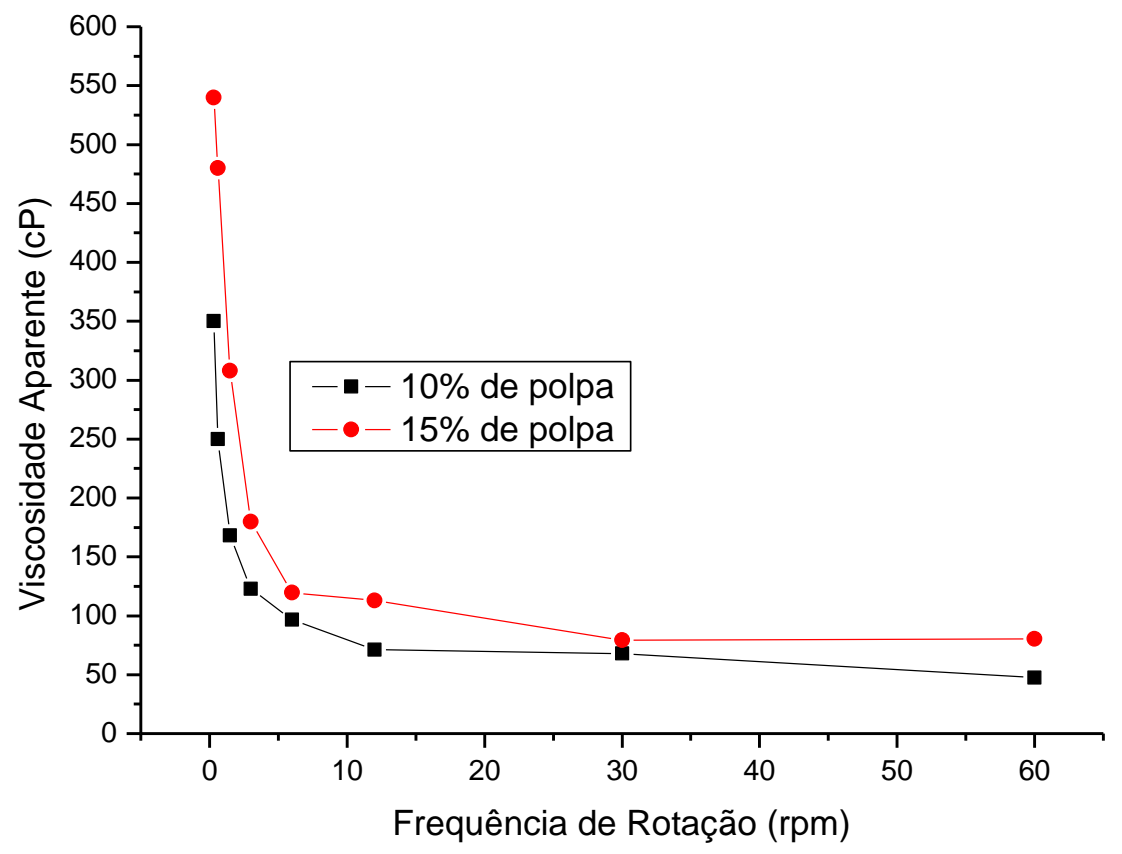

Figura 4: Influência da quantidade de polpa na viscosidade do iogurte elaborado com $5 \%$ de cultura láctea. 
Com relação ao teor de polpa utilizado na formulação, pode-se verificar, que este também exerceu influência nos parâmetros reológicos do iogurte, sendo as amostras com 15\% de polpa as que apresentaram maiores valores de viscosidade, para os diferentes teores de cultura láctica, divergindo com os resultados obtidos por Iodelis (2008) e Aguiar (2009), ao analisarem a influência do teor de polpa de fruta no comportamento reológico do iogurte de goiaba. Uma possível explicação para tal fenômeno seria o fato de que um teor de polpa de goiaba mais elevado diminui o $\mathrm{pH}$ o iogurte (que tem um $\mathrm{pH}$ ideal de 4,5), levando o produto ao dessoramento. Já a polpa de juçara apresenta $\mathrm{pH}$ mais neutro, o que não favoreceu o dessoramento do iogurte, além de contribuir com o aumento de viscosidade do mesmo, já que a viscosidade aparente da polpa de juçara é elevada.

De acordo com as figuras 1 a 4, observa-se que a sua viscosidade aparente de todas as formulações diminuiu com o aumento na frequência de rotação, o que indica um comportamento pseudoplástico, onde a viscosidade aparente decresce com o aumento da tensão de cisalhamento (ou da taxa de deformação). Tais observações estão de acordo com Iodelis (2008), Paolicchi (2009) e Aguiar (2009) .

\section{CONCLUSÃO}

Dos resultados apresentados no item anterior, pode-se concluir que:

- o iogurte de juçara apresentou comportamento reológico típico de um fluido pseudoplástico;

- os teores da cultura lática e da polpa de fruta influenciaram no comportamento reológico do iogurte.

\section{REFERÊNCIAS}

A.O.A.C. Official Methods of Analysis. Washington: Sidney Willians, 1980. 1141p.

AGUIAR, L. F. S. Iogurte de goiaba enriquecido com cereais, correlação da textura com os parâmetros sensoriais. Trabalho de Conclusão de Curso. Universidade de Taubaté, 2010. 52 p.

ALEXANDRE, D., CUNHA, R. L. e HUBINGER, M. D. Conservação do açaí pela tecnologia de obstáculos. Ciência e Tecnologia de Alimentos, vol.24, no.1, p.114-119, 2004.

BLIGH, E. G., DYER, W. J. A rapid method of total lipid extraction and purification, Canadian Journal of of Biochemical Physiology, v.37, p.911-917, 1959. 
GARZÓN, E.; ALONSO, M.L.; MELCÓN, B.; ZAPICO, J. Diseño experimental en reologia de alimentos liquidos y semiliquidos; I. comportamiento de flujo inicial de alimentos infantiles preparados. Alimentaria, v. 27, n. 213, p. 53-57, jun. 1990.

INSTITUTO ADOLFO LUTZ. Normas Analíticas do Instituto Adolfo Lutz. V1: Métodos químicos e físicos para analise. 3. Ed. São Paulo: IMESP, 1985. p.184.

IODELIS, A. Desenvolvimento do iogurte de goiaba enriquecido com aveia: determinação das propriedades reológicas. Trabalho de Conclusão de Curso. Universidade de Taubaté, 2009. $38 \mathrm{p}$.

MORTARA, M.O., VALERIANO, D.M. Modelagem da distribuição potencial do palmiteiro (euterpe edulis martius) a partir de variáveis topográficas, Anais do X SBSR, Foz do Iguaçu, 21-26 abril 2001. INPE, p. 459-471.

NASCIMENTO, R. J. S.; COURI, S.; ANTONIASSI, R.; FREITAS, S.P. Composição em ácidos graxos do óleo da polpa de açaí extraído com enzimas e com hexano. Rev. Bras. Fruticultura, Jun 2008, vol.30, no.2, p.498-502. ISSN 0100-2945

PAOLICCHI, M.F. Iogurte de juçara: formulação e correlação entre os parâmetros reológicos. Trabalho de Conclusão de Curso. Universidade de Taubaté, 2009. 38 p.

PELEGRINE, D.H.G.; MASCIGRANDE, D. D. Polpa de juçara e açaí: diferenças reológicas em função da temperatura e teor de sólidos suspensos. Revista Brasileira de Tecnologia Aplicada nas Ciências Agrárias, v. 4, p. 169-175, 2011.

REIS, M. S.; GUERRA, M. P. Inventário dos Recursos Florestais da Mata Atlântica. Exploração, Utilização dos Recursos, Impactos Atuais e Potencialidades de Manejo. Euterpe edulis Martius (Palmito). Conselho Nacional da Reserva da Biosfera da Mata Atlântica. Universidade Federal de Santa Catarina. Florianópolis, 1999 (no prelo).

SANTANA, L.R.R; SANTOS, L.C.S.; NATALICIO, M.A.; BERNALS, O.L.M.; ELIAS, E.M.; SILVA, C.B.; ZEPKA, L.Q.; MARTINS, I.S.L.; VERNASA, M.G.; PIZARRO, C.C.; BOLINI, H.M.A. Perfil sensorial de iogurte light, sabor pêssego. Ciência e Tecnologia de Alimentos, v.26, n.3, p.619-625, 2006. SGARBIERI, V.C. Propriedades funcionais de proteínas em alimentos. Boletim da Sociedade Brasileira de Ciência e Tecnologia de Alimentos, Campinas, v. 32, n. 1, p. 105-126, jan./ago. 1998.

SILVA, F, C; PELEGRINE, D.H.G.; GASPARETTO, C.A. "Reologia do suco de acerola:efeitos da concentração e da temperatura". Revista da Sociedade Brasileira de Ciência e Tecnologia de Alimentos, v. 25, n.1, p.121-126, 2005. 